\title{
Origin of the Chile Saltpetre
}

$I_{\text {has }}^{\mathrm{N}}$ the Chemiker-Zeitung of February 18, Dr. C. T. Kautter describes some observations which he has made of climatic conditions in Chile, which he believes may throw an interesting light upon the origin of the saltpetre deposits.

In 1924, Prof. Stoklasa suggested that the formation of these beds might be die to a combination of volcanic and bacterial action, the latter being catalysed by radioactivity. In support of his views he investigated a series of samples of caliche in which he was able to determine the existence of $80 \times 10^{-12}$ gm. radium per gram of mineral. That not only the deposits themselves but also the overlying atmosphere should exhibit radioactivity appears to Kautter to be probable though unimportant. He brings forward the suggestion that the formation of nitrates can be explained by well-known physico-chemical changes which are independent of radioactivity.

The district of northern Chile in which the nitrate is found is undoubtedly voleanic in character and the vastness of the deposits and the absence of characteristic fossils have led to the abandonment of the idea that the caliche is of animal or vegetable origin. The violent thunderstorms which occur with great frequency in the high mountains in the summer are accompanied by discharges at such high potentials that the conditions for the production of nitric oxide are most probably fulfilled. Further oxidation of this gas to nitric acid and its subsequent action upon the common salt which is abundantly supplied by volcanic action would lead to the formation of sodium nitrate, but the transference of the latter to the nitrate zone, some hundred kilometres farther westward, is not so easy to comprehend, for the geological evidence seems to be against the idea of transference by sedimentation.

Now it has perhaps not been sufficiently well recognised that the nitrate zone, which extends about $100 \mathrm{~km}$. inland from the coast and lies between lat. $19^{\circ}$ and $26^{\circ} \mathrm{S}$., is particularly subject to the visitation of immense cloud-banks of fog, which rise almost vertically to a height of about $1,000 \mathrm{~m}$ against the coastal heights before being carried inland. Close observation has shown that these banks of cloud operate only within a limited and fairly well-defined area, with its centre at the coast and extending to the prairies or pampas, which lie at distances varying from $30 \mathrm{~km}$. to $80 \mathrm{~km}$. from the coast-line. It is significant that the greatest accumulation of cloud is to be found overlying the zone which is richest in caliche. Now these thick clouds, which often hang for long periods over the nitrate zones, may serve as transporters and condensers of the oxides of nitrogen which are formed by the frequent electric discharges. It is also suggested that nitrogen may become activated during the evaporation of the water, though this has not been experimentally verified.

Good deposits of caliche are frequently found not only in the valleys or plains but also at overhanging cliffs on the mountain-sides, wherever any resistance to the flow of the cloud may be offered. These arrested portions of cloud are eventually dispersed by the sun, when the nitric acid is deposited. Further confirmation of this theory is to be found in the fact that isolated deposits of caliche can be traced to the breaking away in certain areas of patches of cloud which drift away from the main areas of concentration.

Thus the deposits of nitrate are formed by the gradual evaporation of the clouds in the enormous basins in the mountainous regions. Even the relatively high concentration of iodine in the caliche, which has sometimes been quoted as evidence in favour of its production from organic remains, can be satisfactorily accounted for on this theory. The iodine content of the air is particularly great at the sea-level. It is stabilised by oxidation by ozone and nitrogen peroxide to iodic acid. Thus the author draws the interesting conclusion that in this case Nature adopts much the same process as that in operation in modern technology, namely, the combined action of water, air, heat and electricity.

\section{Ecology of the Lucerne 'Flea'}

$\mathrm{T}$ THE so-called lucerne 'flea', Smynthurus viridis, is an insect of the spring-tail group (order Collembola) which is widely spread in Europe. It also occurs in the southern hemisphere, where it has most probably been introduced and, in South Australia, it has become a major pest of lucerne. It is a common insect in Britain and, taking advantage of this fact, Mr. D. Stewart Maclagan has made an extensive study of the rôle of environmental factors in relation to the normal natural increase of the Smynthurus population.

Under the title of "An Ecological Study of the Lucerne 'Flea'", Mr. Maclagan has published (Bull. Entom. Res., 23, 101-145 and 151-190; 1932) observations carried out, in the main, at the Imperial Institute of Entomology Laboratory at Farnham Royal (Bucks). It is not possible to enter into a detailed consideration of the many important points that are discussed by Mr. Maclagan. In addition to studying the bionomics of the insect, and the effects of predators and parasites upon its survival, a critical analysis of the part played by the physical environment is also presented. The influence of temperature, humidity and soil $p \mathrm{H}$ values upon growth, fecundity, and longevity are very fully explored and a general estimate of these combined environmental effects is given. While the first paper is devoted largely to experimental laboratory studies, the second contribution is concerned in the main with the analysis of field data, and the two lines of approach are discussed in conjunction by the author in his conclusions. The value of climatological studies, when checked and analysed by laboratory experimentation, is considered with special reference to the prediction of the possible geographical range of the insect.

The author concludes that the analysis of the complex of environmental factors is an essential preliminary to the study of biological methods of control. The physical environment, he claims, assumes the major rôle in the control of insect populations since it exercises a profound influence on predators, parasites, and hosts alike, resulting in a maze of often unsuspected relationships. Mr. Maclagan's papers form an important contribution to the exact study of animal ecology and are to be commended to the notice of all students of the subject. 